\title{
DEVELOPMENT OF COMPOSITE MATERIAL FOR WIND TURBINE BLADES
}

\author{
P. Y. Andoh ${ }^{1}$, A. Agyei-Agyemang', P. O. Tawiah', C. K. K. Sekyere', C. M. \\ Asante $^{5}$ \\ Department of Mechanical Engineering, Kwame Nkrumah University of Science and \\ Technology, Kumasi, Ghana $a^{1,2,3,4,5}$ \\ pyandoh.coe@gmail.com
}

Received : 01 April 2021, Revised: 09 June 2021, Accepted : 09 June 2021

*Coresponding Author

\begin{abstract}
Rapid increases in the prices of conventional turbine blade making materials as well as future sustainability issues is attracting research interest in the development of polymer composites for turbine blade applications. This study examines the suitability of using a novel bamboo fibre and recycled plastics composite developed for wind turbine blade application. Bamboo fibre was extracted from raw bamboo by chemical and mechanical processes. Recycled High Density Polyethylene (HDPE) was collected, cut into pieces, cleaned and combined with extracted bamboo fibre to form the composite. The percentage ratio of fibre content in the ten specimens ranged from $2.5 \%$ to $25 \%$. A series of mechanical tests were conducted on the specimens, including tensile test, impact test, water absorption test and sun radiation test. Results established that as the percentage of bamboo fibre in the specimen increased, the tensile strength and impact energy also increased. Water absorption and sun radiation tests conducted on specimen $X$ revealed no meaningful impact on its mechanical properties. Hence, the most significant deduction from this study is that the specimen with 25\% bamboo fibre and $75 \%$ HDPE matrix possesses the quality that qualifies it to be used as a material for wind turbine blade fabrication.
\end{abstract}

Keywords : Bamboo Fibre, Composite Materials, Wind Turbine Blades, High Density Polyethylene, Mechanical Tests.

\section{Introduction}

The use of composite materials is common in wind turbine blade production due to their excellent mechanical properties and relatively lower weight compared with the use of steel or other metals (Kalkains, 2019). There is a recent switch toward the common use of carbon fibres and glass fibres among others as synthetic fibres in manufacturing composite materials (Zakikhani, 2014). Glass-fibre reinforced plastics (GRP) is the most widely used composite material in the wind turbine industry because of its desirable mechanical properties and corrosion resistance, high temperature tolerance and relatively cheaper manufacturing cost (Abdul, 2012; Bülent, 2006).

The high energy intensity and costs of carbon fibres make their use in most composite applications not economical (Fitch, 2004). Natural fibres are sometimes used as a substitute in some composite applications instead of carbon fibres. Considering most material selection criteria used in relation to material suitability for wind turbine applications, natural fibre composites have proven to be more suitable for wind turbine blade fabrication with the exception of material strength where glass fibres has been found to be stronger (Constable, 2015). As a matter of fact, there have been a significant increase in numerous applications of natural fibres in various industries due to favourable findings in the economic and environmental friendliness of the properties of natural fibres as against synthetic fibre (Nasir, 2017).

Natural fibres are obtained from plants containing lignocellulose substances and are environmentally friendly due to their $\mathrm{CO} 2$ neutrality, recyclability, renewability, noncarcinogenicity, biodegradability, desirable mechanical properties and the fact that they occur in abundance naturally (Abilash, 2013; Satyanarayana, 2009; Saw, 2014; Shah, 2013; Wang, 2016). Also, when natural fibres are processed as composite materials with thermosetting or 
thermoplastic polymers, they can serve as environmentally friendly alternatives to standard EGlass composites, wood-reinforced materials, and aluminium alloys (Morales, 2017).

Bamboo is one of the natural materials which is being intensively studied to substitute this synthetic fibre since they possess higher strength to weight ratio (Fu, 2012). The potential of bamboo in polymer composite is very important today due to its fibre extraction, structural variation, thermal properties, chemical modification and mechanical properties that make it very suitable for use in the composite industry (Mounika, 2012; Takagi 2013). Bamboo belongs to the family of grass Bambusoideae that comprises cellulose, fibre encapsulated in a lignin matrix (Gutu, 2013). Bamboo can be used in composites as a natural fibre reinforcement in polymer matrices which are petroleum based. Such composites are also called Bamboo Fibre Reinforced Polymer (Abdul, 2012).

Bamboo fibres have provided some good responses in the production of materials that are recyclable, biodegradable and sustainable (Adamu, 2018). Products of composites made from bamboo have several positive advantages such as dimensional stability, longevity, weather resistant, high impact resistant, low maintenance, non-toxic, low flame spread, etc. (Murali, 2013). In the production of safety products, it has been observed that curtains produced from bamboo fibres can absorb electromagnetic radiations (X-ray, infrared) at various wavelengths, making it exclusively less harmful to the human body when compared with other curtains produced from various materials $(\mathrm{Li}, 2012)$. Bamboo also has some disadvantages for various applications, including high moisture content, the difficulty of extracting fine and straight fibres and thermal degradation during manufacturing (Osorio, 2011).

There are two main types of processes used in obtaining bamboo fibres, namely mechanical and chemical processing, depending on the number of times the bamboo fibres will be used and the load it will be subjected to (Adamu, 2018). The mechanical method involves different processes such as steam explosion, retting, crushing, grinding and rolling of the bamboo (Adamu, 2018). A major advantage of fibre extraction using mechanical process over chemical process is a better environmental characteristic of the extracted fibre (Osorio, 2011). It is convenient to divide the fibre extraction process into rough or fine bamboo depending on the preparation method (Nayak, 2016). The rough bamboo fibres are prepared by cutting, boiling, and separation followed by fermenting the bamboo with enzymes, and then it can be washed, bleached with acid treatment, and finally soaked in oil and air-dried (Nayak, 2016).

The chemical process involves yielding of cellulose fibres by alkali hydrolysis before multiphase bleaching is carried out via passing the alkali-treated cellulose fibres through carbon disulphide (CS2). This process is the least time-consuming procedure for yielding bamboo fibres and it is used by most manufacturers (Hunter, 2003).

Numerous researches suggest that bamboo fibre composite has a comparable property to that of polymer composites. This study focuses on the development of a composite material from bamboo fibre and recycled high-density polyethylene matrix for wind turbine blade fabrication.

\section{Materials and Methods}

\subsection{Materials}

Materials used include waste high density polyethylene (HDPE) and green bamboo (Bambusoideae). The properties of the bamboo and the waste plastics that were used are tabulated and presented in Table 1 .

Table 1 - Properties of the samples used.

\begin{tabular}{lcccc}
\hline Material & $\begin{array}{c}\text { Young's Modulus } \\
(\mathrm{GPa})\end{array}$ & $\begin{array}{c}\text { Ultimate Tensile } \\
\text { Strength }(\mathrm{MPa})\end{array}$ & $\begin{array}{c}\text { Fracture Toughness } \\
(\mathrm{MPa})\end{array}$ & $\begin{array}{c}\text { Percentage Elongatior } \\
(\%)\end{array}$ \\
\hline Green Bamboo & $1.2 \pm 0.065$ & $100.3 \pm 11.28$ & $109.23 \pm 5.69$ & - \\
Recycled HDPE & $0.0663 \pm 0.010$ & $16.80 \pm 0.26$ & - & $322.68 \pm 33.4$ \\
\hline
\end{tabular}

Source: (Andoh et al., 2016 ; Tawiah et al., 2016) 


\subsection{Preparation of Fibre and Matrix}

A 10-metre bamboo was harvested from a bamboo farm using a cutlass and cut into pieces of 1-m length. These pieces were then split into strips of $0.25 \mathrm{~m}$ long and immersed in a solution of $400 \mathrm{ml}$ Hydrochloric acid (HCL) which was diluted with 20 litres of water in a black container as shown in Figure 2.1 for 48 hours. This was done to make it soft and also to reduce the lignin content of the bamboo to prevent it from breaking during the fibre extraction.

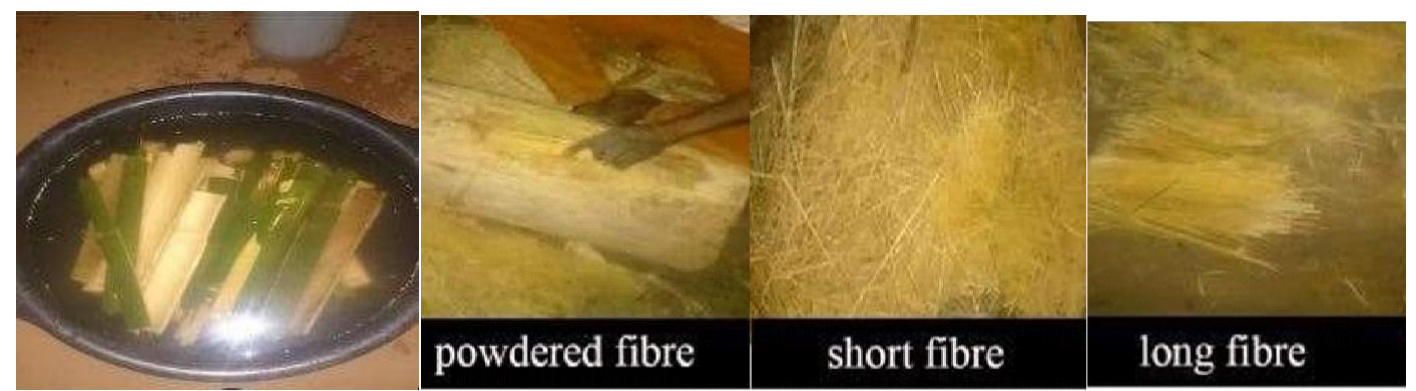

Fig 1. Processing of bamboo fibre and the sample obtained

The wet slabs were removed from the black container and beaten with a wooden mallet to obtain the bamboo fibre as shown in figure 1 three types of fibres were obtained after the extraction process which are long and short fibres and the powdered form as shown in Figure 1. The used high-density polyethylene (HDPE) was collected, washed and cleaned, and allowed to dry. The clean HDPE were cut into pieces using knives and scissors as shown in Figure 2.

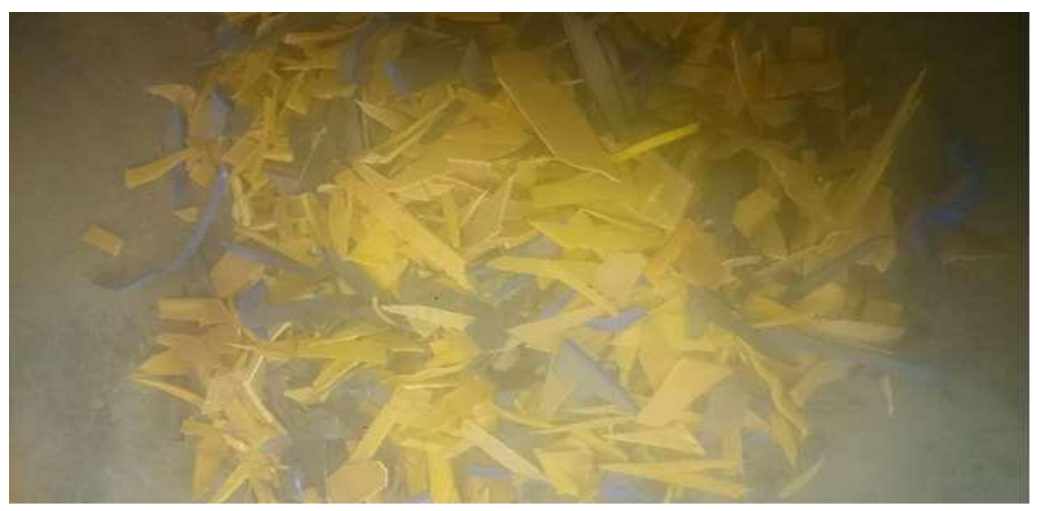

Fig 2. Cut pieces of the waste HDPE

\subsection{Formation of Composite Materials}

A mould was constructed from a high steel metal having dimensions of $250 \mathrm{~mm}$ by $20 \mathrm{~mm}$ by $20 \mathrm{~mm}$ and a cover of $250 \mathrm{~mm}$ by $20 \mathrm{~mm}$ by $5 \mathrm{~mm}$ as shown in figure 3 .

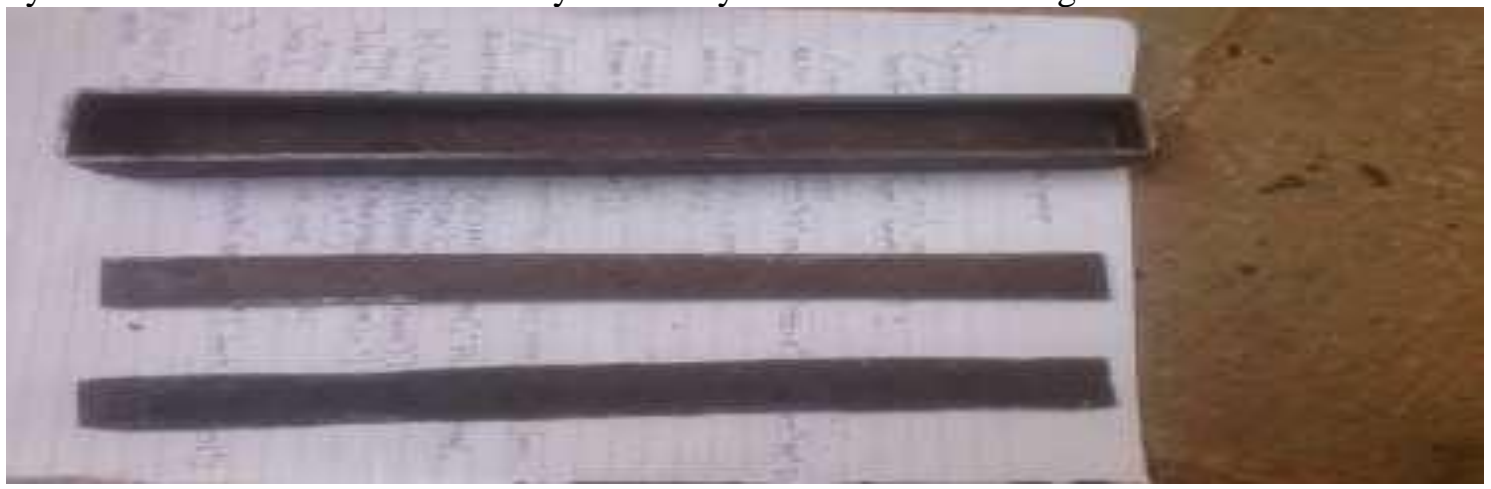

Fig 3. The final mould used in the composite formation

Ten different weight ratios of fibre or plastic in the composite were used (Table 2) to determine the one which will give the highest material strength. The bamboo fibre and the recycled plastic 
composite were formed using the method of casting and hand-laying techniques. Thirty-nine grammes ( $39 \mathrm{~g}$ ) of high-density polyethylene were placed in a saucepan and subjected to heating. Molten HDPE was obtained within 30 to 40 minutes as shown in figure 4.

Table 2

\begin{tabular}{cccc}
\hline Specimen & Mass of Fibre $(\mathrm{g})$ & Mass of HDPE $(\mathrm{g})$ & Total Weight of Specimen $(\mathrm{g})$ \\
\hline I & 1 & 39 & 40 \\
II & 2 & 38 & 40 \\
III & 3 & 37 & 40 \\
IV & 4 & 36 & 40 \\
V & 5 & 35 & 40 \\
VI & 6 & 34 & 40 \\
VII & 7 & 33 & 40 \\
VIII & 8 & 32 & 40 \\
IX & 9 & 31 & 40 \\
X & 10 & 30 & 40 \\
TOTAL & 55 & 345 & 400 \\
\hline
\end{tabular}

Both the conventional fibre glass composite turbine blade and the bamboo composite were installed at the test site at a height of 10 meters and tested under similar operating conditions. Data was collected for both types of blade by monitoring the following parameters: power output, wind velocity, blade rpm and the tip to speed ratio using the turbine control monitor and the values obtained were recorded.

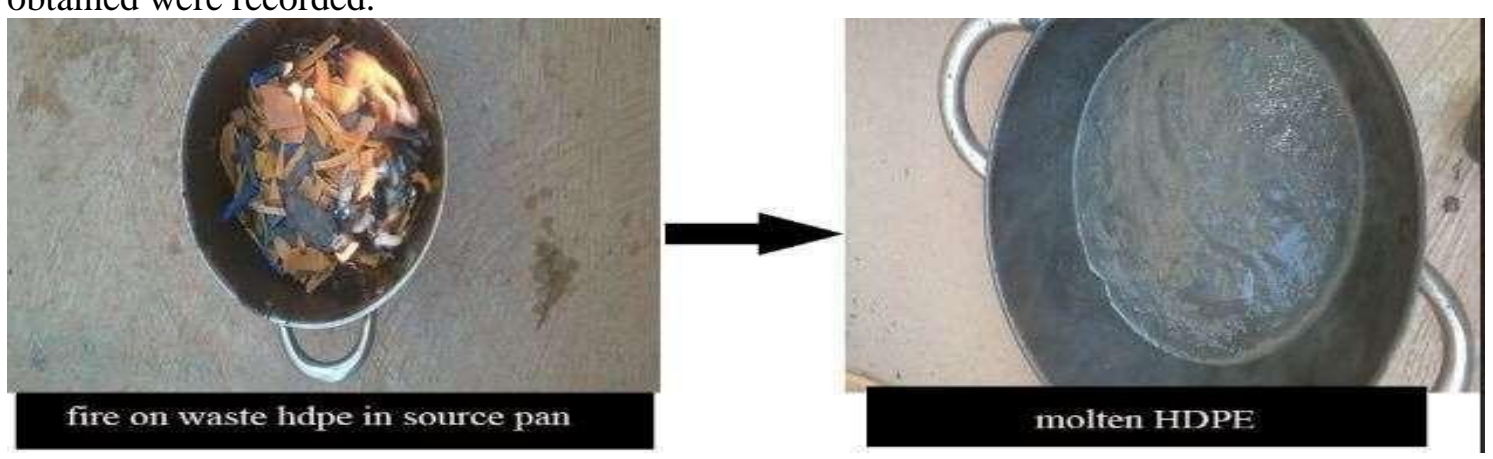

Fig 4. Melting of the shredded HDPE

A white paper was placed in the mould and $0.05 \mathrm{~g}$ of powdered bamboo fibre was then spread on the paper in the mould. About 20\% of molten HDPE was poured into the mould and mixed with the powdered fibre in the mould until a uniform mixture was obtained. $0.95 \mathrm{~g}$ of bamboo fibre was then arranged horizontally in the mould on top of the formed mixture. The remaining $80 \%$ of the molten HDPE was poured into the mould on the horizontally arranged bamboo fibre. The mould was covered and a dead weight of $10 \mathrm{~kg}$ was placed on the mould cover so as to remove any porosity or air bubbles. Figure 2.5 shows the bamboo and HDPE composite after solidification. The process was repeated for the formation of the remaining specimens needed for the mechanical testing. 


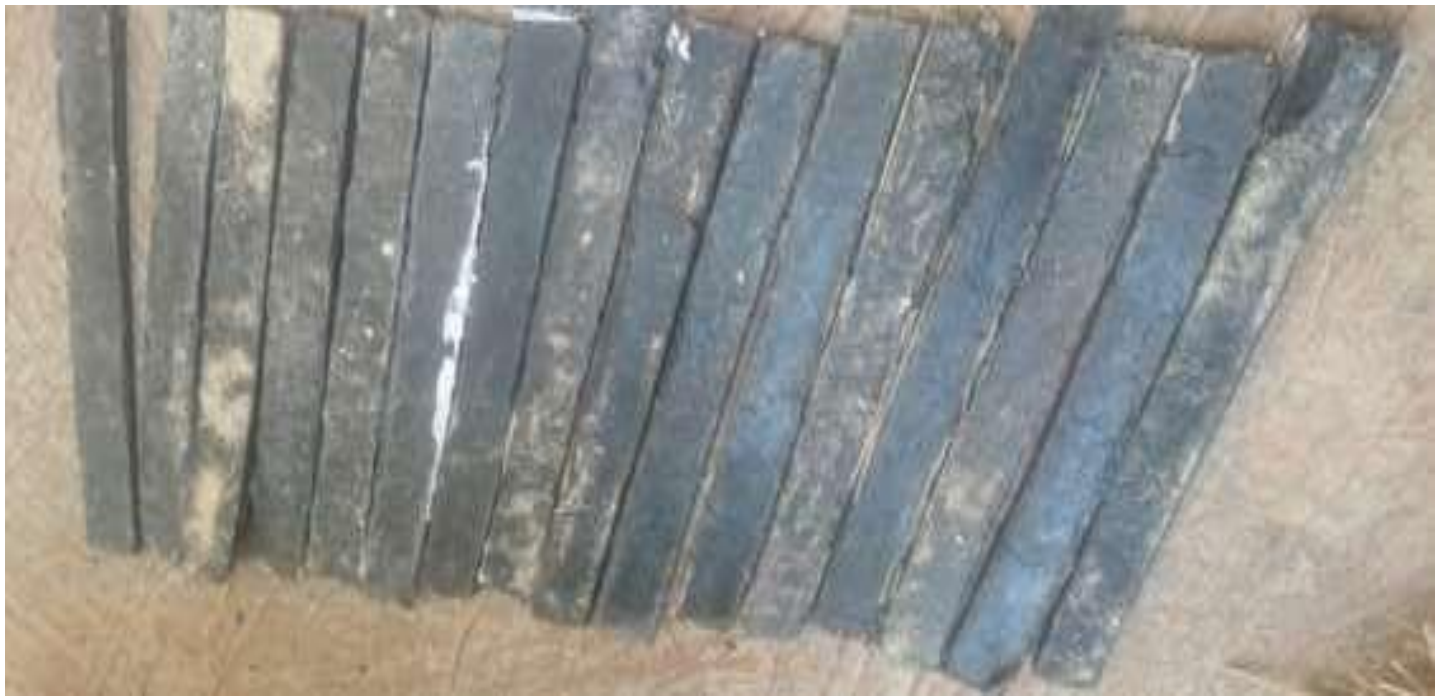

Fig 5. Obtained samples

\subsection{Mechanical Tests}

Four tests were performed to determine the material properties that are widely used as performance indices to assess the suitability of newly-formed materials for typical mechanical applications such as wind turbine blade fabrication for wind energy generation. Typical performance indices measured include; tensile strength, impact resistance, sun radiation properties and water absorption properties.

Five samples for each of the ten specimens were prepared for the tensile test experiment as shown in Figure 6.

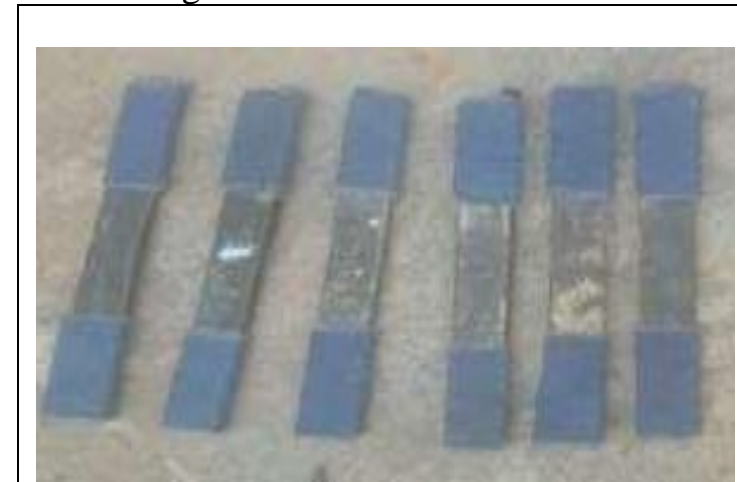

(a) Some of the samples used for the tensile strength test

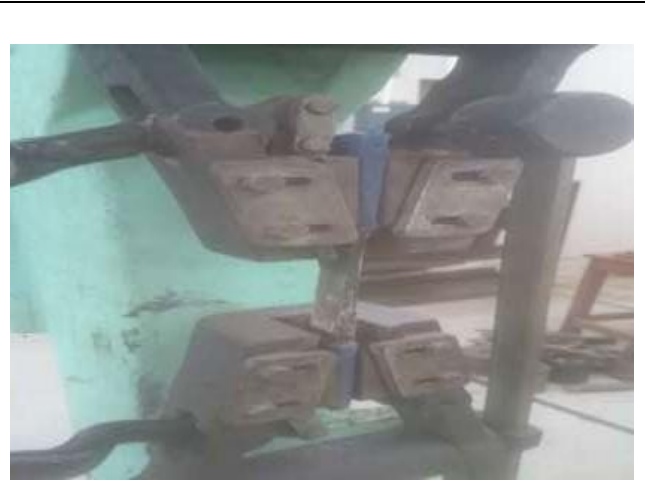

(b) A sample being held in the universal tensile test machine

Fig 6. Tensile Test

For the tensile strength test, the sample is first gripped firmly in two vices attached to the machine (see Figure 2.5(b)). The wheel is then turned to drive the rack and pinion system allowing the gripping part to accommodate the specimen firmly. The sample is then strained to an extension of $1.27 \mathrm{~mm}$ and the corresponding force is then determined by a balance system attached to the machine. The extension and its corresponding force were then recorded. The specimen was given successive further extensions of $1.27 \mathrm{~mm}$ each time and the corresponding force recorded until the material failed. This procedure was repeated for the remaining forty-nine samples and the results were recorded. The plot of the stress versus strain was used to obtain the modulus of elasticity (E), the yield and the ultimate strength. 


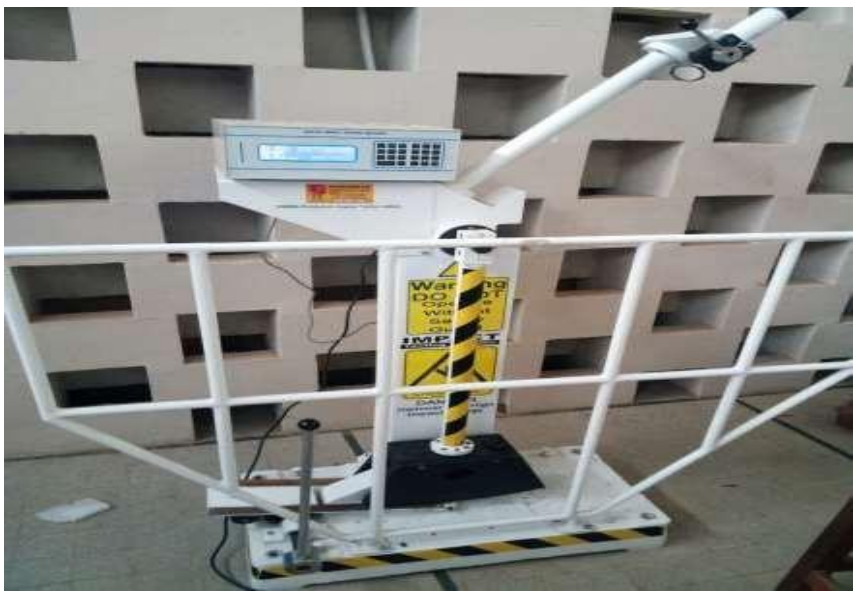

Fig 7. HSM55 Pendulum Impact Tester

Five samples with dimensions $10 \mathrm{~mm}$ by $10 \mathrm{~mm}$ by $55 \mathrm{~mm}$ were prepared for each of the ten specimens for the impact test (see Figure 7 for HSM55 pendulum impact tester set up). A v-notch was made in the middle of all the samples. The pendulum was moved to its lock position. Each sample was clamped into the jig with the notch facing the direction of the pendulum. The pendulum was released using the two-hand release mechanism. The impact energy obtained was recorded. The procedure was repeated for the remaining samples and their respective impact energies recorded. Water absorption test was conducted on the formed composite samples to determine the effect of moisture on the performance of the samples (see Figure 8). This was done to ascertain the performance of the composite material in a humid environment.

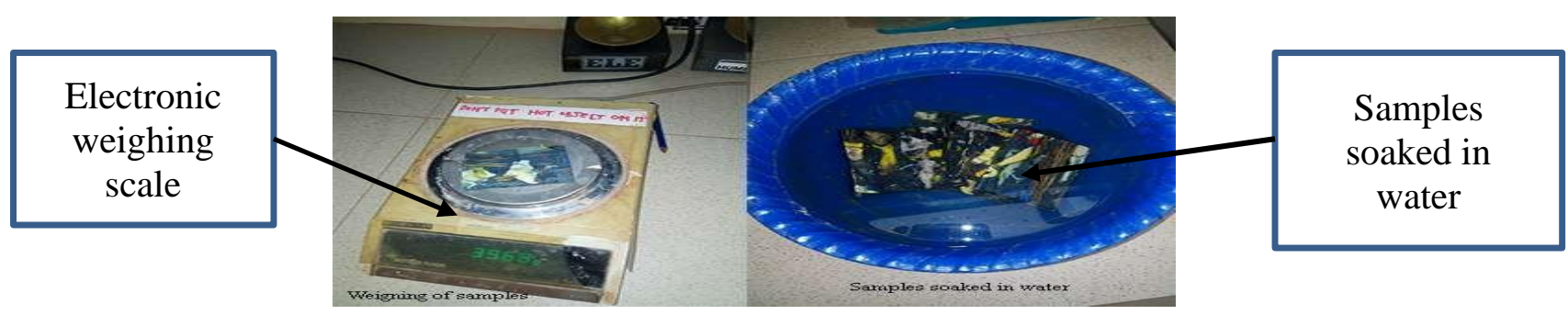

Fig 8. Water absorption test setups

Ten rectangular specimens (five samples each) of dimension $80 \mathrm{~mm} \times 60 \mathrm{~mm}$ and thickness $8 \mathrm{~mm}$ were prepared for this test. Five samples prepared from each specimen were dried in an oven for 24 hours at a temperature of $114^{\circ} \mathrm{C}$. Afterwards, the specimens were removed from the oven and allowed to cool to room temperature. The specimens were then weighed and their initial masses recorded. The specimens were then immersed in water for another 24 hours at room temperature. After 24 hours, the specimens were removed from the water and cleaned. Subsequently, the specimens were weighed to obtain their masses after immersion in water. The masses of the specimens before and after immersion in water were recorded.

Water absorption is expressed as a percentage of increase in weight. Mathematically, percentage water absorbed is given by:

$$
\% \text { water absorption } \frac{\text { Wet Weight-Dry Weight }}{\text { DryWeight }} \times 100 \%
$$

Ten samples of specimen $X$ were prepared for the sun radiation test as shown in Figure 2.10. Specimen $X$ was selected for this test due to the fact that it possesses the highest strength 
among the specimens and this has been proven by the previous experiments. The prepared samples were exposed to sunlight for 14 days (during the day). After the 14 days, the samples were removed from the sun and a tensile test was performed to determine the effect of exposure to solar irradiance on the strength of the specimen selected for this particular test (being specimen two).

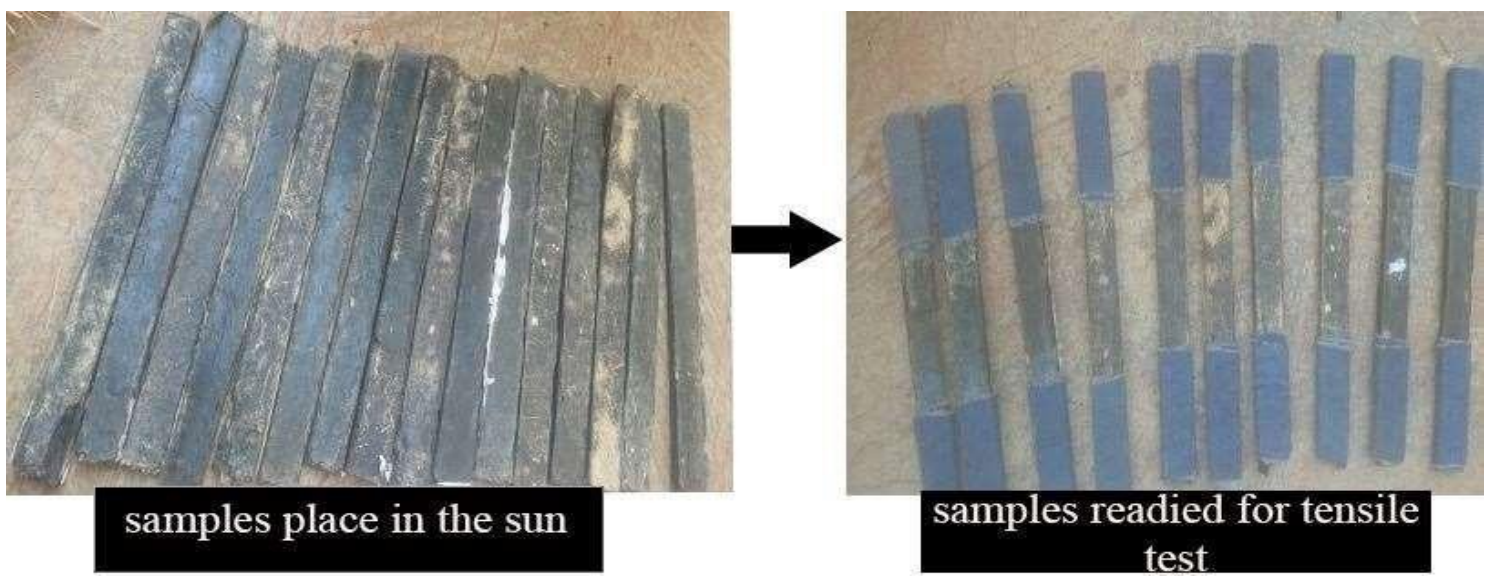

Fig 9. Prepared Samples For The Sun Radiation Test

\section{Results and Discussions}

\subsection{Tensile Test Properties}

Figure 10 shows plots of stress versus strain for Specimen IV, sample 2. The graph was generated using results obtained from the tensile test experiments. From the graph, the yield strength and the ultimate tensile strength were obtained. The gradient of the linear portion of the graph gives the modulus of elasticity.

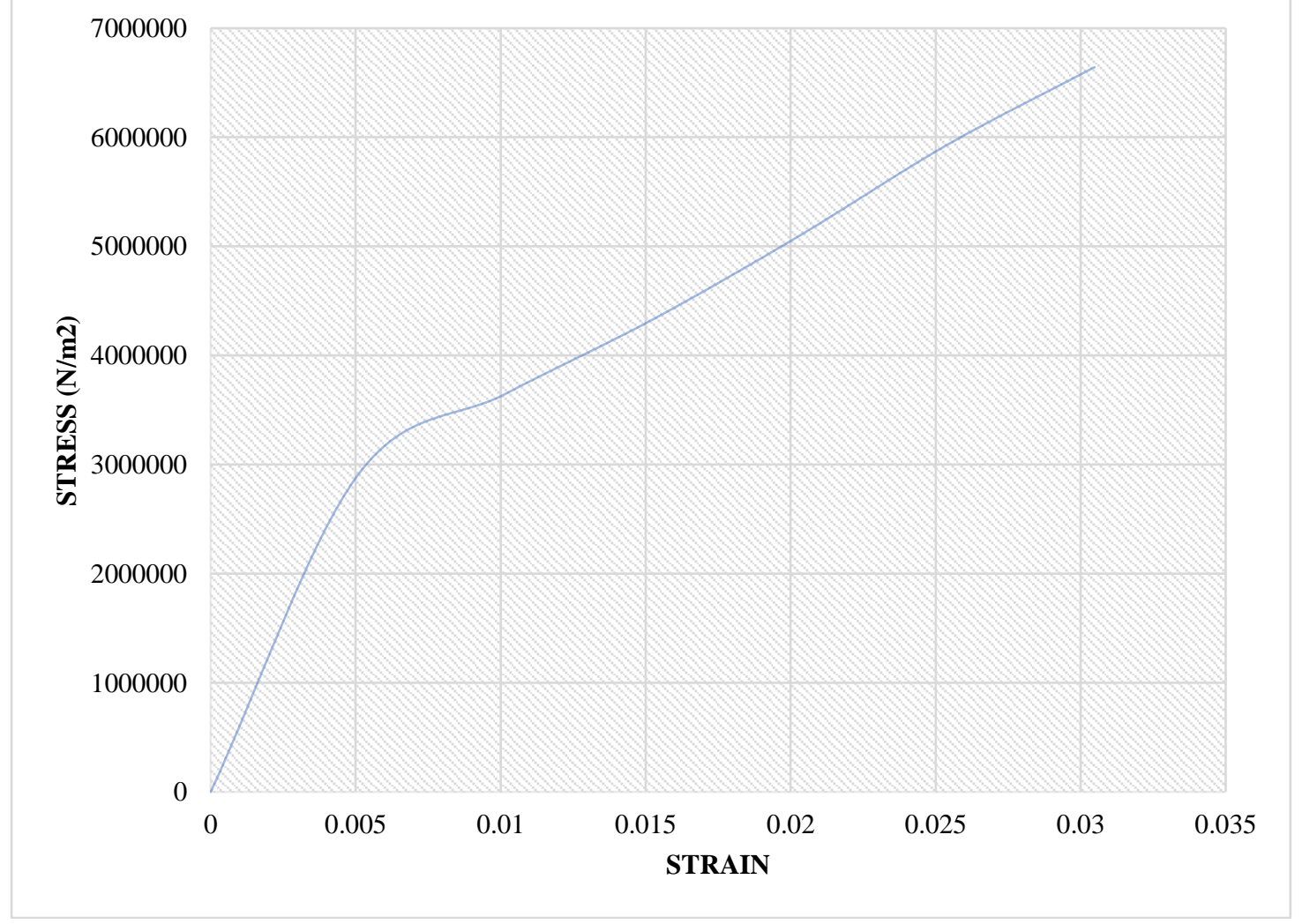

Fig 10. Plot of stress against strain for specimen IV sample 2 
From Figure 10 it is observed that stress is proportional to strain until the composite matrix reaches its yield strength of $2.614 \mathrm{MPa}$. As the strain increases steadily from 0.0508 , the stress also increases appreciably within the elastic region until the stress experienced by the material was $6.50 \mathrm{MPa}$ where the material could not take any more load. From the graph, it can be deduced that the material obeys Hooke's law. This procedure was repeated for the remaining Specimens. It was observed that the values of the yield strength, ultimate tensile strength and modulus of elasticity vary and, therefore, a range will have to be used to represent the strength properties for each specimen. The ranges for the strength properties were determined using Equation 3.1.

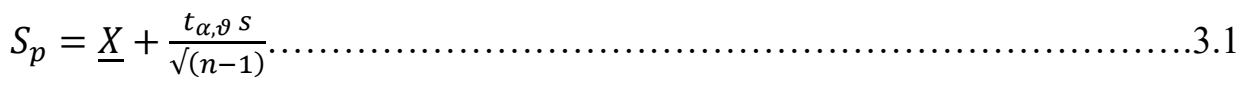

where $S_{p}$ is the strength properties; $\underline{X}$, the mean, $s$, standard deviation, $t_{\alpha, v}$, t-distribution probability, $n$, the sample size (5) and $v$ is $n-1$. But the mean and standard deviation were determined using Equations 3.2 and 3.3 respectively.

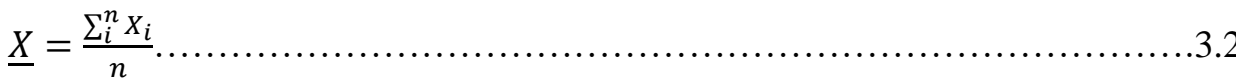

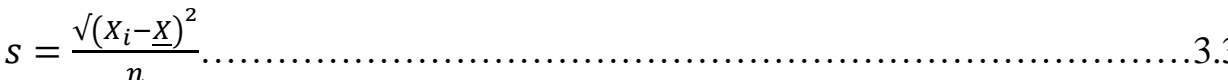

where $X_{i}$ is the strength property of the specimen.

Using a 95\% confidence level, the value of $\mathrm{t}_{0.05,6}$ was 1.94 from the $t$-distribution table. Hence, the three (3) strength properties for the composite materials were computed and the results are represented in Table 3.

Table 3 - Range of modulus of elasticity for the samples

\begin{tabular}{cccc}
\hline Specimens & $\begin{array}{c}\text { Modulus of Elasticity } \\
(\mathrm{MPa})\end{array}$ & Yield Strength (MPa) & $\begin{array}{c}\text { Ultimate Tensile } \\
\text { Strength (MPa) }\end{array}$ \\
\hline I & $0.14 \pm 0.05$ & $1.80 \pm 0.71$ & $3.36 \pm 1.26$ \\
II & $0.13 \pm 0.06$ & $2.34 \pm 0.99$ & $4.67 \pm 0.89$ \\
III & $0.24 \pm 0.05$ & $2.68 \pm 0.64$ & $6.37 \pm 0.14$ \\
IV & $0.14 \pm 0.05$ & $2.61 \pm 0.63$ & $6.50 \pm 0.27$ \\
V & $0.26 \pm 0.09$ & $3.23 \pm 0.59$ & $7.54 \pm 0.48$ \\
VI & $0.30 \pm 0.07$ & $3.33 \pm 0.69$ & $8.61 \pm 0.240$ \\
VII & $0.26 \pm 0.05$ & $3.73 \pm 0.87$ & $9.87 \pm 0.057$ \\
VIII & $0.26 \pm 0.05$ & $3.95 \pm 0.58$ & $16.05 \pm 0.78$ \\
IX & $0.24 \pm 0.05$ & $3.02 \pm 0.62$ & $18.50 \pm 1.81$ \\
X & $0.40 \pm 0.00$ & $5.28 \pm 0.88$ & $26.44 \pm 0.56$ \\
\hline
\end{tabular}

From Table 3, the Yield strength and the Ultimate tensile strength of the tensile test experiment varies directly with increasing percentage of fibre content in the composite. The moduli of elasticity of the specimen show some significant characteristics. The elastic modulus of the specimen does not necessarily increase with increasing fibre content but shows that, the specimen with higher fibre content possess higher values in modulus of elasticity. It can then be concluded that, specimen $\mathrm{X}$ possesses stronger values in tensile strength than the remaining specimens with composition of $25 \%$ bamboo fibre and $75 \%$ HDPE.

\subsection{Impact Test Properties}


The tensile test conducted proved that specimen $\mathrm{X}$ has the highest strength, $26 \mathrm{MPa}$ as compared to the remaining specimens. Specimen X consists of $10 \mathrm{~g}$ of fibre and $30 \mathrm{~g}$ of matrix. It also proved that the ultimate tensile strength and the Young Modulus increase as the amount of fibre content in the matrix increases, though there were some small deviations. To further understand how strong the formed composite is, an impact test was conducted on the specimen. The results obtained are presented in Figure 11.

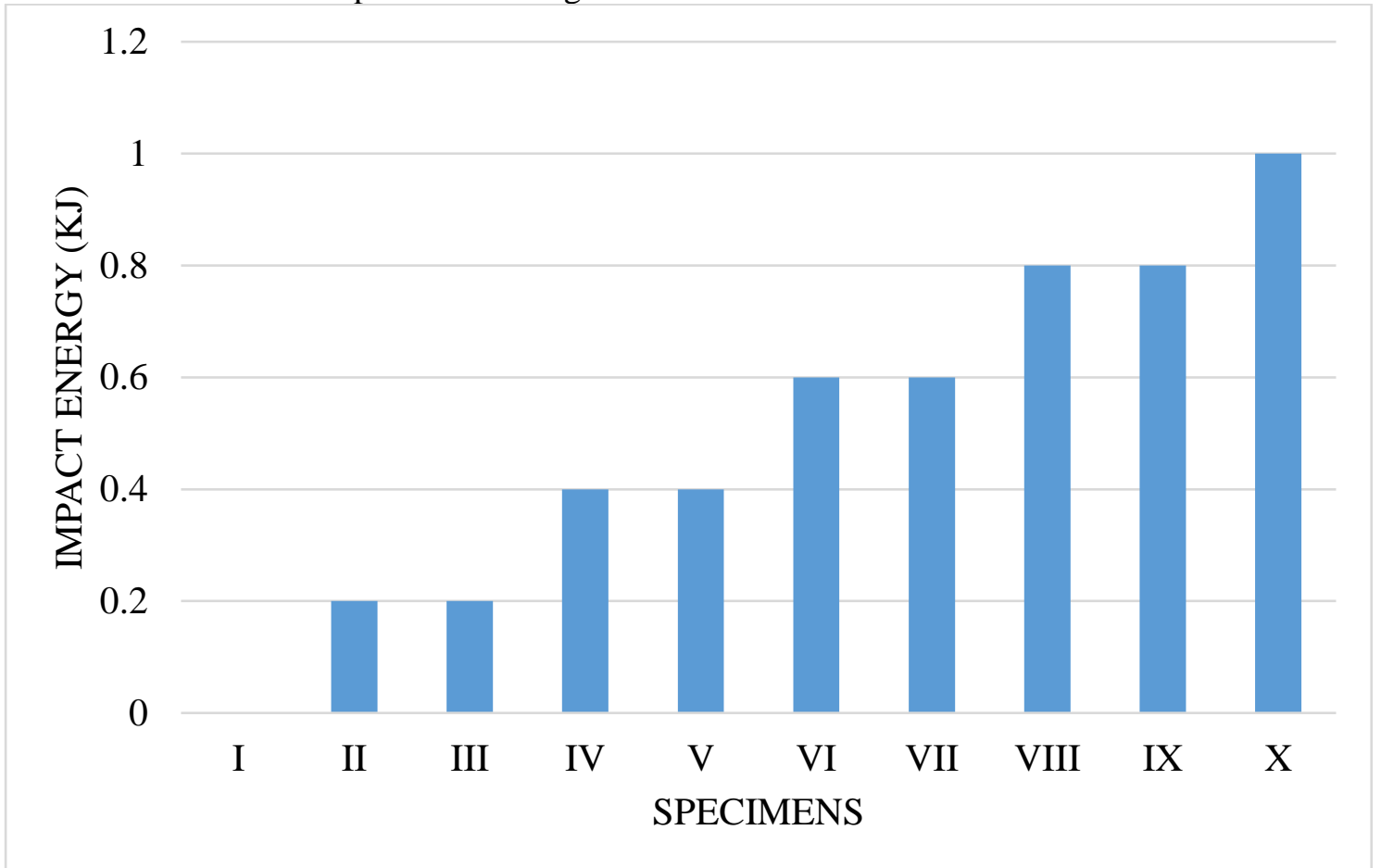

Fig 11. Bar chart of the impact strength of the specimens

From figure 11, sample IX and $X$ tends to have the highest amount of impact energy. The higher the amount of energy absorbed by the specimen the tougher the specimen. Sample IX and $\mathrm{X}$ have the highest impact energy of $0.8 \mathrm{~J}$ and $1.0 \mathrm{~J}$ respectively. This proves that, increasing the fibre content in the composite increases its strength.

\subsection{Sun Radiation Test Properties}

Ten samples of Specimen $\mathrm{X}$ were placed in the sun for 14 days to check for possible changes in strength after the exposure. Figure 12 shows a plot of stress against strain for Specimen X sample 1. The plot has two parts, a linear part and a curved part. From Figure 3.3 the yield strength was 4.59 MPa and the ultimate tensile strength was 26.6 MPa. The slope of the plot gives the Young's modulus which was determined to be $400 \mathrm{MPa}$ or $0.4 \mathrm{GPa}$. This was repeated for the remaining samples. It was observed that the values of the yield strength, ultimate tensile strength and modulus of elasticity vary and therefore a range will have to be used to represent the strength properties for each specimen. The ranges for the strength properties were determined using Equation 3.1 to 3.3. The results were then compared with the first test for the specimen $\mathrm{X}$ as presented in Table 4. 


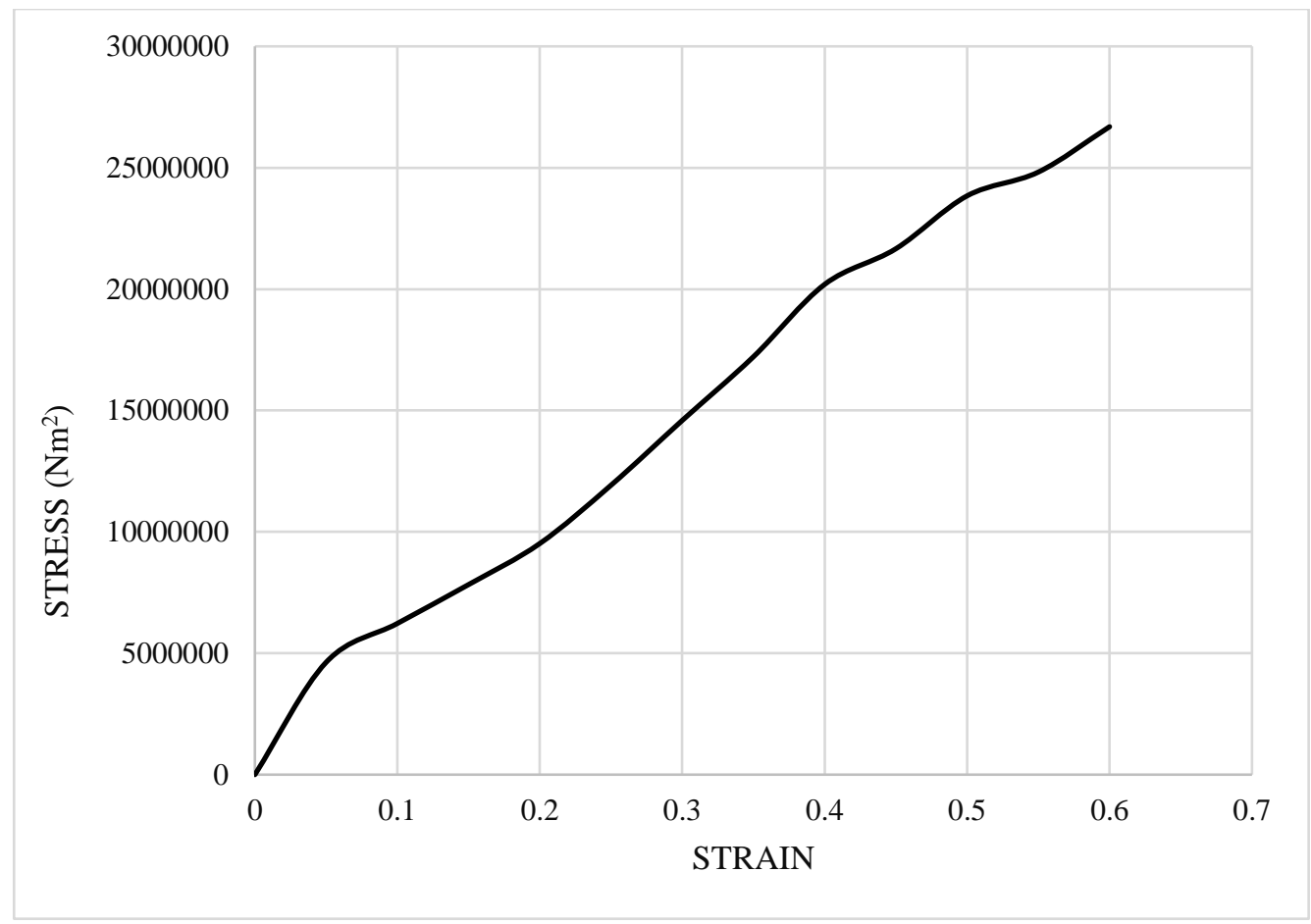

Fig 12. Plot of stress against strain for Specimen X sample I

Table 4 - Cost breakdown of the Bamboo Plastic Composite and the Glass conventional turbine Blade

\begin{tabular}{lccc}
\hline Conditions & $\begin{array}{c}\text { Modulus of } \\
\text { Elasticity }(\mathrm{MPa})\end{array}$ & $\begin{array}{c}\text { Yield Strength } \\
(\mathrm{MPa})\end{array}$ & $\begin{array}{c}\text { Ultimate Tensile } \\
\text { Strength (MPa) }\end{array}$ \\
\hline After Sun Radiation & $0.40 \pm 0.00$ & $4.80 \pm 0.33$ & $26.40 \pm 0.35$ \\
Before Sun Radiation & $0.40 \pm 0.00$ & $5.28 \pm 0.88$ & $26.44 \pm 0.56$ \\
\hline
\end{tabular}

Comparing the values of specimen $\mathrm{X}$ from the tensile test experiment to that of the sun radiation test shows that the sun has no effect at all on the formed composite. The ultimate tensile strength of specimen $X$ from the tensile test experiment is $(26.4 \pm 0.56) \mathrm{MPa}$ and that of the sun radiation test is $(26.4 \pm 0.35) \mathrm{MPa}$. The obtained values of modulus of elasticity for specimen $\mathrm{X}$ for tensile test and sun radiation test are 4.0 GPa and 4.0GPa respectively. The values for the yield

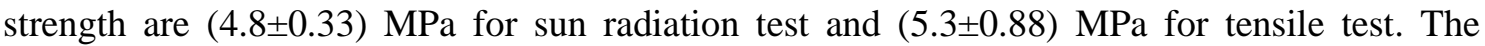
differences between these values are almost zero or negligible. From the data obtained, the sun radiation has no significant effect on the tensile strength of specimen $\mathrm{X}$.

\subsection{Water Absorption Test}

Using Equation 2.1, the water absorbed and percentage water absorbed by specimen I were determined. It was observed that the value for the percentage water absorbed varies and therefore a range will be used to represent the percentage water absorbed. Hence using Equations 3.1 to 3.3, the water absorbing ranges for all the specimens were determined and the results are shown in Table 5.

Table 5 - Water Absorption test results

\begin{tabular}{cc}
\hline Specimen & \% Water Absorbed \\
\hline I & $2.86 \pm 0.06$ \\
III & $2.76 \pm 0.08$ \\
III & $3.07 \pm 0.09$ \\
IV & $7.50 \pm 0.08$
\end{tabular}




\begin{tabular}{cc} 
V & $5.11 \pm 0.09$ \\
VI & $5.46 \pm 0.15$ \\
VII & $4.30 \pm 0.05$ \\
VIII & $2.81 \pm 0.08$ \\
IX & $2.40 \pm 0.06$ \\
X & $6.55 \pm 0.09$ \\
\hline
\end{tabular}

From table 5, it can be deduced that the amount of water absorbed does not depend on the amount of fibre in the composite. It is observed that, specimen IV absorbed more water compared to the remaining specimens even though it has less fibre component with percentage ratio of 1:9 ( $4 \mathrm{~g}$ of fibre and $36 \mathrm{~g}$ of matrix). Specimen $\mathrm{X}$ which has a fibre ratio of 1:3 (10 $\mathrm{g}$ of fibre and 30 $\mathrm{g}$ of matrix) recorded the second highest moisture absorbing capacity. The test also revealed that the amount of water absorbed depends on the length of exposure of the fibres in the composites. Thus, to avoid water absorption by the fibres in the composite, the fibres should be completely covered by the matrix. If the fibre is not completely covered by the matrix, it will absorb some amount of water when exposed to a humid environment for a particular time interval. Despite the large fibre content in Specimen X, none of the samples prepared from this Specimen absorbed more than $7.5 \%$ of water when exposed to water for $24 \mathrm{hrs}$.

\section{Conclusion and Recommendation}

This study was carried out to determine whether bamboo fibre and waste high density polyethylene composite will be suitable for the production of wind turbine blades. Bamboo fibre was extracted from raw bamboo using chemical and mechanical processes.

The tensile test conducted showed that the composite with the highest percentage $(25 \%$, i.e. specimen X) of bamboo fibre had the highest strength value of $26 \mathrm{MPa}$. The results obtained for the impact test also showed that as the percentage of bamboo fibre increases the impact strength also increases with specimen $\mathrm{X}$ recording an impact energy of $1.0 \mathrm{~J}$. The outcome of water absorption test showed that the amount of moisture absorbed after 24 hours of immersion in water is insignificant and also does not depend on the percentage of bamboo fibre in the composite. Results further showed that the sun radiation has no noticeable effect on the tensile strength of specimen X. It can then be concluded that the bamboo fibre and recycled HDPE composite possess desirable mechanical properties to be considered for use as material for wind turbine blade fabrication.

\section{Areas Requiring Further Studies}

In order to improve the mechanical properties of the composite material it is recommended that further studies be conducted to:

- Determine the effect of controlling the rate of solidification on the mechanical properties of the resulting composite material.

- Investigate the use of other bamboo fibre extraction methods on the mechanical properties of the composite material.

\section{References}

Abilash, N., \& Sivapragash, M. J. K. S. U. (2016). Optimizing the delamination failure in bamboo fiber reinforced polyester composite. Journal of King Saud University-Engineering Sciences, 28(1), 92-102.

Constable, G., Llewellyn, D., Walford, S. A., \& Clement, J. D. (2015). Cotton breeding for fiber quality improvement. In Industrial crops (pp. 191-232). Springer, New York, NY.

Eker, B., Akdogan, A., \& Vardar, A. (2006). Using of composite material in wind turbine blades. Journal of Applied Sciences, 6(14), 2917-2921.

Fitch P.E., \& Cooper J.S., (2004). Life cycle energy analysis as a method for material selection. Trans ASME 2004; 126:798-804. 
Hunter, I. R. (2002). Bamboo resources, uses and trade: the future?. J Bamboo Rattan, 2, 1-19.

Kalkanis, K., Psomopoulos, C. S., Kaminaris, S., Ioannidis, G., \& Pachos, P. (2019). Wind turbine blade composite materials-End of life treatment methods. Energy Procedia, 157, 11361143.

Khalil, H. A., Bhat, I. U. H., Jawaid, M., Zaidon, A., Hermawan, D., \& Hadi, Y. S. (2012). Bamboo fibre reinforced biocomposites: A review. Materials \& Design, 42, 353-368.

Muhammad, A., Rahman, M. R., Hamdan, S., \& Sanaullah, K. (2019). Recent developments in bamboo fiber-based composites: a review. Polymer bulletin, 76(5), 2655-2682.

Morales, A. P., Maciel, R. N., Silva, V. D., \& Silva, A. D. S. (2011). Tempo de reação motora no Voleibol. Perspectivas online: Biologia e saúde, 3(1), 42-49.

Qin, L., Wen-Ji, Y., \& Yang-lun, Y. (2012). Research on properties of reconstituted bamboo lumber made by thermo-treated bamboo bundle curtains. Forest Products Journal, 62(78), 545-550.

Zhang, X., Fu, J., Paulo, A. C., Yu, C., \& Guebitz, G. M. (2012). Bioprocessing of bamboo materials. 